\title{
Cloning, analysis and functional annotation of expressed sequence tags from the Earthworm Eisenia fetida Mehdi Pirooznia ${ }^{\dagger 1}$, Ping Gong ${ }^{\dagger 2}$, Xin Guan ${ }^{2}$, Laura S Inouye ${ }^{3}$, Kuan Yang1, Edward J Perkins*3 and Youping Deng*1
}

\author{
Address: ${ }^{1}$ Department of Biological Sciences, University of Southern Mississippi, Hattiesburg, MS, 39406, USA, ${ }^{2}$ SpecPro Inc., 3909 Halls Ferry Rd \\ Vicksburg, MS, 39180, USA and ${ }^{3}$ Environmental Laboratory, U.S. Army Engineer Research and Development Center, 3909 Halls Ferry Rd, \\ Vicksburg, MS, 39180, USA \\ Email: Mehdi Pirooznia - Mehdi.Pirooznia@usm.edu; Ping Gong - Ping.Gong@erdc.usace.army.mil; \\ Xin Guan - Xin.Guan@erdc.usace.army.mil; Laura S Inouye - Laura.S.Inouye@erdc.usace.army.mil; Kuan Yang - Kuan.Yang@usm.edu; \\ Edward J Perkins* - Edward.J.Perkins@erdc.usace.army.mil; Youping Deng* - Youping.Deng@usm.edu \\ * Corresponding authors †Equal contributors
}

from Fourth Annual MCBIOS Conference. Computational Frontiers in Biomedicine New Orleans, LA, USA. I-3 February 2007

Published: I November 2007

BMC Bioinformatics 2007, 8(Suppl 7):S7 doi:I0.1 I86/I47I-2105-8-S7-S7

This article is available from: http://www.biomedcentral.com/I47I-2105/8/S7/S7

(c) 2007 Pirooznia et al; licensee BioMed Central Ltd.

This is an open access article distributed under the terms of the Creative Commons Attribution License (http://creativecommons.org/licenses/by/2.0), which permits unrestricted use, distribution, and reproduction in any medium, provided the original work is properly cited.

\begin{abstract}
Background: Eisenia fetida, commonly known as red wiggler or compost worm, belongs to the Lumbricidae family of the Annelida phylum. Little is known about its genome sequence although it has been extensively used as a test organism in terrestrial ecotoxicology. In order to understand its gene expression response to environmental contaminants, we cloned 4032 cDNAs or expressed sequence tags (ESTs) from two $E$. fetida libraries enriched with genes responsive to ten ordnance related compounds using suppressive subtractive hybridization-PCR.
\end{abstract}

Results: A total of 3144 good quality ESTs (GenBank dbEST accession number EH669363EH672369 and EL5I5444-EL5I5580) were obtained from the raw clone sequences after cleaning. Clustering analysis yielded 223 I unique sequences including 448 contigs (from I 36 I ESTs) and I783 singletons. Comparative genomic analysis showed that 743 or $33 \%$ of the unique sequences shared high similarity with existing genes in the GenBank $\mathrm{nr}$ database. Provisional function annotation assigned 830 Gene Ontology terms to 517 unique sequences based on their homology with the annotated genomes of four model organisms Drosophila melanogaster, Mus musculus, Saccharomyces cerevisiae, and Caenorhabditis elegans. Seven percent of the unique sequences were further mapped to 99 Kyoto Encyclopedia of Genes and Genomes pathways based on their matching Enzyme Commission numbers. All the information is stored and retrievable at a highly performed, webbased and user-friendly relational database called EST model database or ESTMD version 2.

Conclusion: The ESTMD containing the sequence and annotation information of 4032 E. fetida ESTs is publicly accessible at http://mcbc.usm.edu/estmd/. 


\section{Background}

As key representatives of the soil fauna, earthworms are essential in maintaining soil fertility through their burrowing, ingestion and excretion activities [1]. There are over 8000 described species worldwide, existing everywhere but in Polar and arid climates [2]. They are increasingly recognized as indicators of agroecosystem health and ecotoxicological sentinel species because they are constantly exposed to contaminants in soil. The earthworm species (e.g., Eisenia fetida, Eisenia andrei, and Lumbricus terrestris) widely used in standardized acute and reproduction toxicity tests belong to the Lumbricidae family (phylum, Annelida; class, Clitellata; subclass Oligochaeta; order, Haplotaxida; superfamily, Lumbricoidea; family, Lumbricidae). E. fetida and E. andrei are two sibling species commonly found in North American composters and are sold commercially for fish bait. They have a life span of 4-5 years and are obligatorily amphimictic even though each worm has both male and female reproductive organs [3].

Like many other ecologically important species, genomics research in earthworms lags far behind other model species such as Mus musculus and Caenorhabditis elegans. In the absence of full genome sequences, expressed sequence tags (ESTs) allow rapid identification of expressed genes by sequence analysis and are an important resource for comparative and functional genomic studies. ESTs are often generated from either end of randomly selected cDNA clones and provide valuable transcriptional data for the annotation of genomic sequences. Because of recent advances in biotechnology, ESTs are produced daily in large quantities, with nearly 42 million entries in the current GenBank db EST database (release 030207). Nevertheless, it is still a challenging bioinformatics problem to analyze and annotate the often short, redundant and yet error prone EST sequences in an appropriate and efficient manner, especially when the genome sequence of the organism is unknown. Recent years have seen some EST projects undertaken with L. rubellus [4] and E. andrei [5], which have generated 19,934 and 1,108 ESTs, respectively (db EST release 030207). Before this study, there were only 96 nucleotide and 89 protein Entrez records found for E. fetida. In the present study, we cloned, sequenced and analyzed 4032 ESTs from E. fetida. We used suppression subtractive hybridization-PCR (SSH) to enrich cDNAs responsive to ten ordnance related compounds (ORCs). This work is part of a larger effort to identify candidate molecular biomarkers for rapid, mechanism-based gene expression assays to supplement current acute and reproductive toxicity tests. The specific objectives of this study were (1) to isolate and characterize cDNAs from $E$. fetida that can be used to monitor exposure to ORCs, and (2) to make the E. fetida EST information publicly accessible by integrating it to our web-based EST model organ- ism database (ESTMD) so that it can be shared with interested parties.

\section{Results cDNA library and EST sequence analysis}

We cloned a total of 4032 cDNAs from the two SSH libraries (see Methods for details). We transformed and picked 2208 clones from forward subtracted cDNA pools and 1824 from the reverse subtracted cDNA pools. After running on 96-well gel electrophoresis, 216 clones were found to be false positives with no inserts or had more than one insert. We sequenced the remaining 3816 clones producing 3144 good quality sequences with an average length of 310 bases. We batch-deposited them in the GenBank db EST under accession numbers EH669363EH672369 and EL515444-EL515580. Clone sequences that were too short ( $<50$ bases) or of poor quality $(<50$ good quality bases, see methods for quality criteria) were excluded from further analysis. The observed failure rate (18\%) is typical for high-throughput sequencing [6]. The deposited, cleaned sequences were further assembled into 2231 clusters (or unique sequences) on the basis of sequence similarity and quality. Nearly $80 \%$ or 1783 of the clusters produced were singletons, and $80 \%$ of the remaining 448 contigs (average length $=428$ bases) were assembled from 2 or 3 clone sequences (Figure 1). The highest number of sequences assembled into one contig was 30 . The most represented putative genes in our libraries are Cd-metallothionein, cytochrome oxidase, chitotriosidase, actin, ATP synthase, Nahoda protein, lysozyme, SCBP (soluble calcium binding protein), ferritin, troponin T, lumbrokinase, and myohemerythrin (Table 1).

\section{Comparative sequence analysis}

We used the 2,231 unique sequences to search non-redundant protein databases using blastx [6-8]. A total of 743 sequences (33\% of all unique sequences) matched known proteins with cut-off expect $(E)$ values of $10^{-5}$ or lower, among which 71 (3\%) had E-values between $10^{-100}$ and $10^{-50}, 309(14 \%)$ between $10^{-50}$ and $10^{-20}$, and $363(16 \%)$ between $10^{-20}$ and $10^{-5}$ (Table 2 ). A total of 880 unique sequences had less meaningful matches $\left(E>10^{-5}\right)$. The remaining 608 sequences $(27 \%)$ had no matches. We also examined unique E. fetida sequences to determine similarity to the genes of four model organisms Drosophila melanogaster, Mus musculus, Saccharomyces cerevisiae, and Caenorhabditis elegans. A total of 830 blastx matches were found for 517 E. fetida unique sequences (23\%) at the cutoff E-value of $10^{-5}$ (Table 3 ). Some E. fetida ESTs matched genes conserved between the four organisms. More than $50 \%$ of the matches came from the mouse genome, whereas only 5 matches were found in the yeast genome. These results suggest that earthworms may be more evolutionarily distant from the yeast than from the other three organisms. 


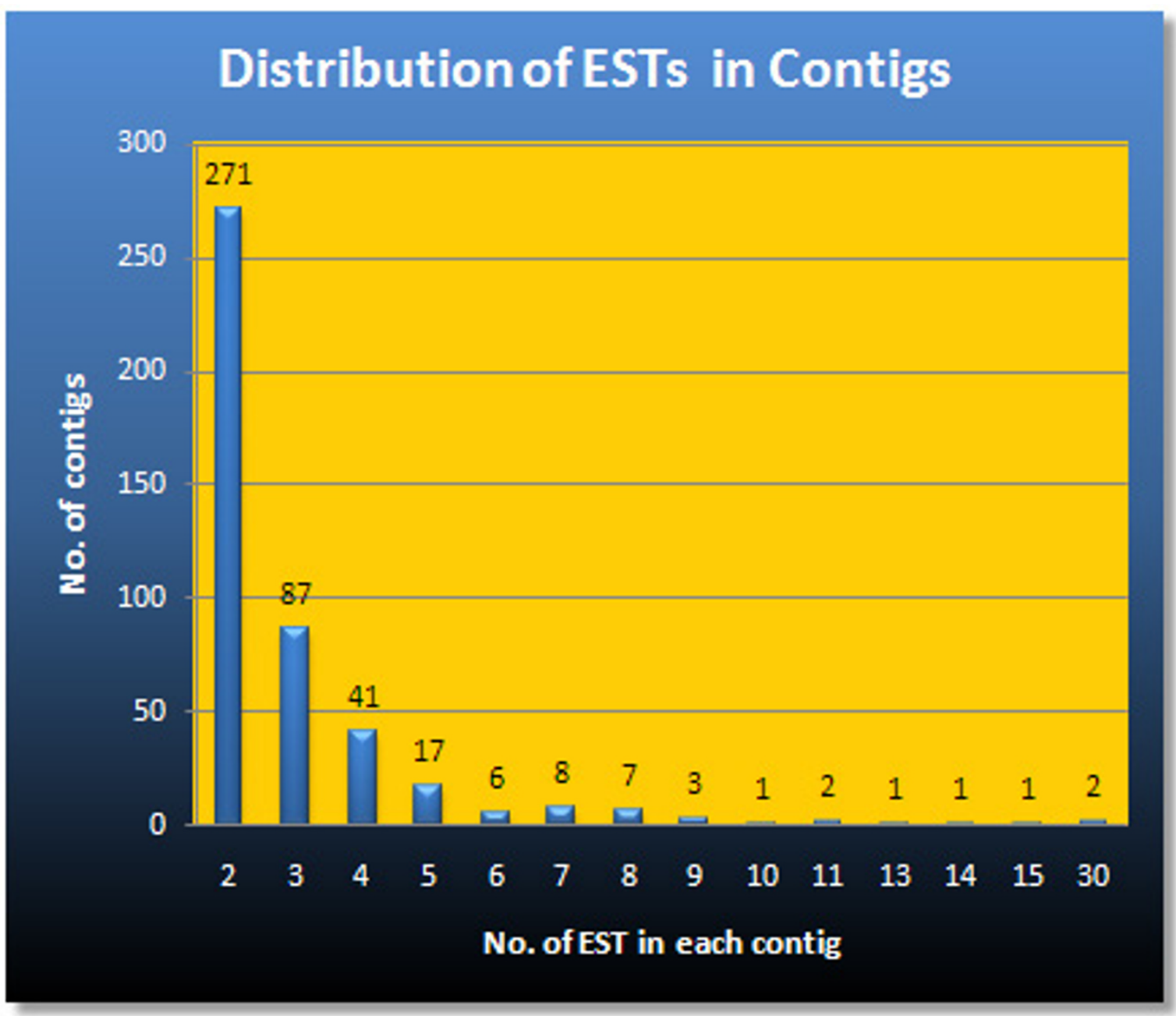

Figure I

Distribution of 1361 good quality ESTs in 448 assembled contigs.

\section{Functional classification}

We adopted the Gene Ontology (GO) annotation of the aforesaid four model organisms to interpret the function of the E. fetida ESTs [6-8]. Each unique sequence of E. fet$i d a$ was assigned the same gene functions of the best blastx hit genes $\left(E \leq 10^{-5}\right)$ in these model organisms' genome. The assigned GO terms for the unique sequences are categorized and outlined in Table 4 (biological process), Table 5 (molecular function), and Table 6 (cellular component). A complete listing of all the GO mappings is available in Additional file 1. The most represented molecular function is "binding" accounting for 51\% of the total 517 unique sequences assigned with at least one GO term (Table 5), whereas those for biological processes are "cellular process" (39\%) and "physiological process" $(40 \%)$ (Table 4$)$. In terms of the final child GO categories, the most frequently assigned biological processes are "protein metabolism" (12.5\%), "cellular macromolecule metabolism" (11.7\%), and "cellular protein metabolism" (11\%) under both cellular and physiological processes (Table 4), whereas those for molecular functions are "hydrolase activity" (11\%) and "protein binding" (10\%) (Table 5). The largest subcategory in cellular components is "intracellular organelle" $(23.6 \%)$ under both the intracellular part and the organelle (Table 6).

\section{Pathway assignment}

We assigned the unique E. fetida sequences to a specific Kyoto Encyclopedia of Genes and Genomes (KEGG) pathway based on their matching Enzyme Commission (EC) numbers. A total of 157 unique sequences (accounting for $7 \%$ of all unique sequences) including 28 contigs and 129 singletons matched enzymes with an EC number. Fiftyeight unique sequences are involved in two or more path- 
Table I: The most represented putative genes in the Eisenia fetida cDNA libraries

\begin{tabular}{|c|c|c|c|c|c|c|c|c|}
\hline Contig & ESTs & Length & $\begin{array}{l}\text { Accession } \\
\text { Version \# }\end{array}$ & bit & E-value & Identities & Organism & Description \\
\hline Contig423 & 7 & 452 & AAH69614.I & 336 & $\mathrm{I} .00 \mathrm{E}-30$ & $64 / 137$ & Homo sapiens & CHITI protein \\
\hline Contig424 & 7 & 480 & CAEI8I|8.1 & 205 & $2.00 \mathrm{E}-15$ & $40 / 58$ & Lumbricus terrestris & SCBP3 protein \\
\hline Contig426 & 7 & 659 & AAW25147.I & I7| & $5.00 \mathrm{E}-\mathrm{II}$ & $42 / 83$ & Schistosoma japonicum & SJCHGC00665 protein \\
\hline Contig427 & 7 & 494 & CAA48798.I & 714 & $3.00 \mathrm{E}-74$ & $132 / 135$ & Podocoryne carnea & actin \\
\hline Contig428 & 7 & 230 & $\underline{B A C 06447.1}$ & 195 & $3.00 \mathrm{E}-14$ & $37 / 76$ & Haemaphysalis longicornis & chitinase \\
\hline Contig428 & 7 & 230 & NP 001020370.1 & 182 & $1.00 \mathrm{E}-12$ & $36 / 73$ & Homo sapiens & chitinase 3 -like 2 isoform c \\
\hline Contig429 & 7 & 439 & $\underline{A B C 60436.1}$ & 749 & $2.00 \mathrm{E}-78$ & $145 / \mid 46$ & Hirudo medicinalis & cytoplasmic actin \\
\hline Contig43I & 8 & 397 & $\underline{A A \times 51817.1}$ & 383 & $5.00 \mathrm{E}-36$ & $73 / 100$ & Diloma arida & actin \\
\hline Contig434 & 8 & 579 & CAA65364.I & 971 & I.00E-104 & $189 / 189$ & Lumbricus terrestris & Actin \\
\hline Contig435 & 8 & 601 & AAA96|44.1 & 322 & I.00E-28 & $62 / 134$ & Hirudo medicinalis & destabilase I \\
\hline Contig436 & 8 & 810 & XP 394202.2 & 217 & $3.00 \mathrm{E}-16$ & $47 / 162$ & Apis mellifera & $\begin{array}{l}\text { PREDICTED: similar to } \\
\text { GAII808-PA }\end{array}$ \\
\hline Contig436 & 8 & 810 & EAL25702.1 & 216 & $4.00 \mathrm{E}-16$ & $51 / 183$ & Drosophila pseudoobscura & GAII808-PA \\
\hline Contig437 & 8 & 394 & AAX77000.1 & 552 & I.00E-55 & $110 / 122$ & Metaphire feijani & cytochrome c oxidase subunit I \\
\hline Contig438 & 9 & 1055 & EAR81082.I & 127 & $\mathrm{I} .00 \mathrm{E}-05$ & $27 / 60$ & Tetrahymena thermophila & $\begin{array}{l}\text { hypothetical protein } \\
\text { TTHERM_02141640 }\end{array}$ \\
\hline Contig440 & 9 & 472 & NP 008244.I & 439 & $2.00 \mathrm{E}-42$ & $96 / 152$ & Lumbricus terrestris & $\begin{array}{l}\text { ATP6_10599 ATP synthase F0 } \\
\text { subunit } 6\end{array}$ \\
\hline Contig442 & II & 449 & CAA65364.I & 760 & I.00E-79 & $147 / \mid 47$ & Lumbricus terrestris & Actin \\
\hline Contig443 & II & 846 & NP 008239.1 & 256 & I.00E-20 & $57 / 105$ & Lumbricus terrestris & $\begin{array}{l}\text { COX2_10599 cytochrome c } \\
\text { oxidase subunit II }\end{array}$ \\
\hline Contig444 & 13 & 894 & $\underline{\mathrm{AAH}} 69614.1$ & 614 & $4.00 \mathrm{E}-62$ & $128 / 294$ & Homo sapiens & CHITI protein \\
\hline Contig446 & 15 & 584 & AAX62723.1 & 576 & $4.00 \mathrm{E}-58$ & $122 / 166$ & Eisenia fetida & cytochrome oxidase subunit I \\
\hline Contig448 & 30 & 488 & CAAI5423.1 & 246 & $5.00 \mathrm{E}-20$ & $40 / 41$ & Eisenia fetida & metallothionein \\
\hline
\end{tabular}

ways. The remaining 99 pathway-assigned sequences are mapped to only one pathway. Eighty-two unique sequences $(52 \%$ of total) containing 14 contigs and 68 singletons were assigned to metabolism pathways (Table 7 and complete listing available in Additional file 2). Amino acid metabolism has the highest number of assigned pathways, followed by carbohydrate metabolism, energy metabolism, translation, and signal transduction. Genes putatively coded by a singleton EW1_F1plate05_B07 (enoyl coenzyme A hydratase) and Contig 251 (thioredoxin peroxidase) are most versatile, which are mapped to 10 and 8 pathways, respectively.

\section{ESTMD (EST Model Database) web application}

The ESTMD is a highly performed, web-accessible and user-friendly relational database [6]. It facilitates and enhances the retrieval and analysis of EST information by providing a number of comprehensive tools for mining raw, cleaned and clustered EST sequences, GO terms and KEGG pathway information as well as a variety of webbased services such as BLAST search, data submission and sequence download. The application is developed using advanced Java technology (Jsp and Servlets) and it supports portability, extensibility and data recovery. It can be accessed at http://mcbc.usm.edu/estmd/. The workflow process is as follows: Users input keywords or IDs from the web interface and then submit them as a query to the server. The server processes the query and retrieves date from the backend database through the database connection interface. The results are processed and sent to the users in proper formats.

The main ESTMD tables are clone, contigview, est new, flybase, geneon, gomodels, pathway, term, uniseqhit, master_search and unisequence (Figure 2). Main sequence information including ECnumber, Labname, raw and clean sequence, and vector information are stored in the master_search table.

\section{Discussion}

Using SSH-PCR we enriched earthworm cDNAs responsive to exposure of ten ORCs that represent three classes of chemicals, i.e., nitroaromatics (2,4-dinitrotoluene, 2,6dinitrotoluene, 2,4,6-trinitrotoluene (TNT), and trinitrobenzene), heterocyclic nitroamines (1,3,5-trinitroperhydro-1,3,5-triazine or RDX and 1,3,5,7-tetranitro1,3,5,7-tetrazocane or HMX) and heavy metals $(\mathrm{Cd}, \mathrm{Cu}$, $\mathrm{Zn}$ and $\mathrm{Pb}$ ) (Figures 3 and 4). Exposure times varied from 4-d to 28-d to capture gene expression changes at different time points. In consideration of the magnitude of effort required by this study, we selected a single dose for each compound. We also believe that differentially expressed transcripts captured on the time scale may represent to a certain degree those manifested on the dosage scale, and vise versa. We chose time over dosage mainly because we are more interested in early indication of later effects. We 
Table 2: Homology analysis of the 223 I unique Eisenia fetida EST sequences based on the results from BLASTX against NCBI's nr database

\begin{tabular}{|c|c|c|c|c|c|c|}
\hline \multirow[b]{2}{*}{ Homology } & \multicolumn{2}{|c|}{ Contig } & \multicolumn{2}{|c|}{ Singleton } & \multicolumn{2}{|l|}{ Total } \\
\hline & $\mathbf{N}$ & $\%$ & $\mathbf{N}$ & $\%$ & $\mathbf{N}$ & $\%$ \\
\hline $10^{-150}<E \leq 10^{-100}$ & 0 & 0 & 0 & 0 & 0 & 0 \\
\hline $10-100<E \leq 10^{-50}$ & 38 & 8 & 33 & 2 & 71 & 3 \\
\hline $10^{-50}<\mathrm{E} \leq 10^{-20}$ & 93 & 21 & 216 & 12 & 309 & 14 \\
\hline $10^{-20}<\mathrm{E} \leq 10^{-5}$ & 78 & 17 & 285 & 16 & 363 & 16 \\
\hline Total meaningful match $\left(E \leq 10^{-5}\right)$ & 209 & 46 & 534 & 30 & 743 & 33 \\
\hline Less meaningful match $\left(E>10^{-5}\right)$ & 165 & 37 & 715 & 40 & 880 & 40 \\
\hline No match (No hit) & 74 & 17 & 534 & 30 & 608 & 27 \\
\hline Total & 448 & 100 & 1783 & 100 & 2231 & 100 \\
\hline
\end{tabular}

purposely mixed the RNA samples from different exposures for library construction because of the large variety of chemicals and exposure length, compared to the relatively small amount of resources available. The cloned cDNAs may not represent genes responding to one specific compound because each chemical, especially each class of chemicals, is likely to have specific mode of action involving different genes. Nevertheless, this library construction strategy served our downstream purpose of making CDNA microarrays with the isolated cDNA clones even though we cannot identify which cDNA or groups of cDNAs responded to which compound and at which exposure time point using the raw EST data. The combination of SSH-PCR and CDNA microarray analysis has been a widely used approach for identifying differentially expressed genes $[9,10]$ and characterizing mechanisms of action of known and suspected toxicants $[11,12]$, especially when there is no or little genomic information available for the test organism. Our microarray studies have generated data enabling us to further identify differentially expressed transcripts and to elucidate sublethal toxicological mechanisms in E. fetida exposed to TNT alone [13] or a mixture of TNT and RDX [14].

It is worth noting that the comparative sequence analysis (23\%) and functional classification (7\%) based on GO and KEGG analysis only found a small portion of the ESTs highly homologous $\left(E \leq 10^{-5}\right)$ with well-annotated genes. Nevertheless, the functions of these ESTs are widely dis- tributed representing 830 different GO terms and 99 different KEGG pathways. Notably, genes putatively involved in carbohydrate, energy and amino acid metabolism, cellular processes of endocrine, immune, nervous and sensory systems, signal transduction, DNA transcription, RNA translation and post-translation splicing are identified suggesting that the ten ORCs may have affected a wide range of important pathways.

From candidate biomarker gene point of view, we found repeatedly the existence of some toxicant-specific E. fetida mRNAs in our libraries (Table 1 and Additional file 3). For instance, the expression of metallothionein (MT) mRNA, the most abundant transcript in our cDNA libraries, is reportedly a sensitive and early genetic biomarker of metal exposure [15-18]. Demuynck et al. [15] demonstrated that a single exposure to $8 \mathrm{mg} \mathrm{Cd} / \mathrm{kg}$ of dry soil for 1 day induced MT mRNA. Brulle et al. [16] observed changes in MT mRNA expression as early as $14 \mathrm{hr}$ after exposure. There are also clear differences of MT gene expression between worms exposed to different $\mathrm{Cd}$ concentrations $(8,80$ or $800 \mathrm{mg} \mathrm{Cd} / \mathrm{kg}$ of dry soil) [15]. Copper is an essential element for the activity of a number of physiologically important enzymes including cytochrome c oxidase (COX), $\mathrm{Cu} / \mathrm{Zn}$-superoxide dismutase (SOD), and dopamine-beta-hydroxylase (DBH). However, exposure to a toxic level of copper can not only induce MT for Cu sequestration [17] but also alter the expression of COX (Table 1), SOD and DBH genes (Additional file 3). Fur-

Table 3: Comparison of significant homologous matches $\left(E \leq 10^{-5}\right)$ to four model organisms of the $223 \mathrm{I}$ unique Eisenia fetida EST sequences. The full listing of matches is available in Additional file I.

\begin{tabular}{lll}
\hline Organism Name & Number of matches & \% of unique sequences \\
\hline Drosophila melanogaster & 265 & $12 \%$ \\
Mus musculus & 447 & $20 \%$ \\
Saccharomyces cerevisiae & 5 & $0.2 \%$ \\
Caenorhabditis elegans & 113 & $5 \%$ \\
Total matches & $\mathbf{8 3 0}$ & $\mathbf{2 3} \%$ \\
Total unique sequences & $\mathbf{5 1 7}$ & \\
\hline
\end{tabular}


Table 4: Distribution of Gene Ontology biological process terms assigned to Eisenia fetida unique sequences on the basis of their homology to the annotated genome of four model organisms. The number of total matches is 830 as shown in Table 3 and the full listing is available in Additional file 2.

\begin{tabular}{|c|c|c|}
\hline Gene Ontology term & Unique sequences & Percentage of total matches \\
\hline cellular process & 328 & $39.52 \%$ \\
\hline cell communication & 52 & $6.27 \%$ \\
\hline cellular physiological process & 309 & $37.23 \%$ \\
\hline cell organization and biogenesis & 62 & $7.47 \%$ \\
\hline cellular metabolism & 255 & $30.72 \%$ \\
\hline cellular biosynthesis & 46 & $5.54 \%$ \\
\hline cellular macromolecule metabolism & 97 & $11.69 \%$ \\
\hline cellular protein metabolism & 92 & $11.08 \%$ \\
\hline regulation of cellular physiological process & 48 & $5.78 \%$ \\
\hline transport & 71 & $8.55 \%$ \\
\hline regulation of cellular process & 51 & $6.14 \%$ \\
\hline development & 51 & $6.14 \%$ \\
\hline physiological process & 331 & $39.88 \%$ \\
\hline cellular physiological process & 309 & $37.23 \%$ \\
\hline cell organization and biogenesis & 62 & $7.47 \%$ \\
\hline cellular metabolism & 255 & $30.72 \%$ \\
\hline cellular macromolecule metabolism & 97 & $11.69 \%$ \\
\hline localization & 53 & $6.39 \%$ \\
\hline metabolism & 272 & $32.77 \%$ \\
\hline biosynthesis & 70 & $8.43 \%$ \\
\hline cellular metabolism & 255 & $30.72 \%$ \\
\hline cellular biosynthesis & 46 & $5.54 \%$ \\
\hline cellular macromolecule metabolism & 97 & $11.69 \%$ \\
\hline cellular protein metabolism & 92 & $11.08 \%$ \\
\hline organic acid metabolism & 10 & $1.20 \%$ \\
\hline macromolecule metabolism & 181 & $21.81 \%$ \\
\hline biopolymer metabolism & 58 & $6.99 \%$ \\
\hline cellular macromolecule metabolism & 97 & $11.69 \%$ \\
\hline macromolecule biosynthesis & 34 & $4.10 \%$ \\
\hline protein metabolism & 96 & $11.57 \%$ \\
\hline primary metabolism & 164 & $19.76 \%$ \\
\hline protein metabolism & 104 & $12.53 \%$ \\
\hline regulation of physiological process & 51 & $6.14 \%$ \\
\hline regulation of biological process & 57 & $6.87 \%$ \\
\hline response to stimulus & 47 & $5.66 \%$ \\
\hline
\end{tabular}

ther research is required to establish dose-dependent gene expression in both laboratory and field conditions.

\section{Conclusion}

This study presented a framework for cloning, analyzing and annotating differentially expressed ESTs from the oligochaete E. fetida. A total of 2231 unique sequences were clustered from 3144 good quality clones, among which $743(33 \%)$ share high similarity with existing genes in the GenBank nr database. We assigned 830 GO terms to 517 unique sequences based on their homology with the annotated genomes of four model organisms Drosophila melanogaster, Mus musculus, Saccharomyces cerevisiae, and Caenorhabditis elegans. Seven percent of the unique sequences were further mapped to 99 KEGG pathways. All the sequence and annotation information is accessible at http://mcbc.usm.edu/estmd/.

\section{Methods}

\section{cDNA library construction}

Two earthworm cDNA libraries were constructed using SSH-PCR [19]. Earthworms (E. fetida) were maintained in continuous culture from stocks obtained from Carolina Biological Supply (Burlington, NC). Worms were kept in moistened sphagnum peat ( $\mathrm{pH}$ 6.5-7.5, moisture content $50 \%$ ), and were fed ad libitum on a diet of Magic Worm Food (Carolina Biological Supply). Fully clitellate adults weighing 0.3-0.6 g (live weight) were selected for all experiments.

The first SSH library (Figure 3) was made using pooled mRNA $(10 \mu \mathrm{g})$ extracted from control unexposed worms against worms exposed to Cd $(2.6 \mathrm{mmol} / \mathrm{kg}$ or $292 \mathrm{mg} /$ $\mathrm{kg}$ ), TNT (100 mg/kg), 2,6-DNT (54 mg/kg), RDX (50 mg/ $\mathrm{kg})$, or HMX $(10 \mathrm{mg} / \mathrm{kg})$. For the construction of the sec- 
Table 5: Distribution of Gene Ontology molecular function terms assigned to Eisenia fetida unique sequences on the basis of their homology to the annotated genome of four model organisms. The number of total matches is 830 as shown in Table 3 and the full listing is available in Additional file 2.

\begin{tabular}{|c|c|c|}
\hline Gene Ontology term & Unique sequences & Percentage of total matches \\
\hline antioxidant activity & 2 & $0.24 \%$ \\
\hline binding & 426 & $51.33 \%$ \\
\hline carbohydrate binding & 18 & $2.17 \%$ \\
\hline cofactor binding & 6 & $0.72 \%$ \\
\hline ion binding & 84 & $10.12 \%$ \\
\hline lipid binding & 5 & $0.60 \%$ \\
\hline metal cluster binding & 3 & $0.36 \%$ \\
\hline neurotransmitter binding & 3 & $0.36 \%$ \\
\hline nucleic acid binding & 53 & $6.39 \%$ \\
\hline nucleotide binding & 68 & $8.19 \%$ \\
\hline pattern binding & 10 & $1.20 \%$ \\
\hline peptide binding & 4 & $0.48 \%$ \\
\hline protein binding & 90 & $10.84 \%$ \\
\hline tetrapyrrole binding & 5 & $0.60 \%$ \\
\hline vitamin binding & 2 & $0.24 \%$ \\
\hline catalytic activity & 194 & $23.37 \%$ \\
\hline helicase activity & 4 & $0.48 \%$ \\
\hline hydrolase activity & 94 & $11.33 \%$ \\
\hline isomerase activity & 8 & $0.96 \%$ \\
\hline ligase activity & 7 & $0.84 \%$ \\
\hline lyase activity & 11 & $1.33 \%$ \\
\hline oxidoreductase activity & 46 & $5.54 \%$ \\
\hline small protein activating enzyme activity & 3 & $0.36 \%$ \\
\hline transferase activity & 27 & $3.25 \%$ \\
\hline enzyme regulator activity & 16 & $1.93 \%$ \\
\hline motor activity & 4 & $0.48 \%$ \\
\hline nutrient reservoir activity & 2 & $0.24 \%$ \\
\hline signal transducer activity & 26 & $3.13 \%$ \\
\hline structural molecule activity & 47 & $5.66 \%$ \\
\hline transcription regulator activity & 16 & $1.93 \%$ \\
\hline translation regulator activity & 13 & $1.57 \%$ \\
\hline transporter activity & 33 & $3.98 \%$ \\
\hline
\end{tabular}

ond library (Figure 4), mRNA $(10 \mu \mathrm{g})$ from worms exposed to $\mathrm{Cu}(293 \mathrm{mg} / \mathrm{kg}), \mathrm{Pb}(8778 \mathrm{mg} / \mathrm{kg}), \mathrm{Zn}(357$ $\mathrm{mg} / \mathrm{kg}), 2,4-\mathrm{DNT}$ (100 mg/kg), and TNB (100 mg/kg) was run against mRNA from another set of control worms. Exposures (4-, 14-, or 28-d) were conducted in an Organization for Economic Cooperation and Development (OECD) artificial soil consisting of 70\% sand, 20\% kaolin clay, and 10\% 2-mm sieved peat moss with an adjusted $\mathrm{pH}$ between 6.5 and 7.0. Chemical concentrations were selected at effective concentrations for $50 \%\left(\mathrm{EC}_{50}\right)$ reduction in fecundity on the basis of our previous studies as well as published literature.

Exposed and unexposed earthworms were fixed in RNAlater (Ambion, Austin, TX) and stored at $-80^{\circ} \mathrm{C}$. Total RNA was extracted using RNeasy kits (Qiagen, Valencia, CA), and poly(A) mRNA was separated from total RNA using NucleoTrap mRNA purification kit (BD Biosciences, San Jose, CA). The integrity and concentration of both total and mRNA were checked on an Agilent 2100 Bioan- alyzer (Palo Alto, CA). The gel-like images generated by the Bioanalyzer show that both RNAs have only one bright band close to the $2 \mathrm{~kb}$ ladder band (Figures 5 \&6), which is distinctive from the two bands seen with $18 \mathrm{~S}$ and 26S RNA of mammalian RNA. A Clontech PCR-Select ${ }^{\mathrm{m}}$ cDNA subtraction kit (BD Biosciences) was then used to enrich for differentially expressed genes (Figure 7).

\section{EST cloning and sequencing}

After the secondary PCR amplification, both forward and reverse subtracted PCR products of the two libraries were cloned using pCR2.1 or pCR4.0 vectors and Mach1-T1 chemically competent cells (Invitrogen, Carlsbad, CA). Positive colonies were picked and grown overnight at $37^{\circ} \mathrm{C}$ in $\mathrm{LB}$ media containing $50 \mu \mathrm{g} / \mathrm{mL}$ ampicillin in a 96-deep well block format. Half of the clone culture (300 $\mu \mathrm{l})$ was archived with $300 \mu \mathrm{l}$ of $60 \%$ glycerol and stored at $-80^{\circ} \mathrm{C}$. Two $\mu \mathrm{l}$ of the remaining clone culture was amplified in a 100- $\mu$ l PCR reaction. After amplification, $8 \mu \mathrm{l}$ of the PCR reaction was checked on a 96-well electrophore- 
Table 6: Distribution of Gene Ontology cellular component terms assigned to Eisenia fetida unique sequences on the basis of their homology to the annotated genome of four model organisms. The number of total matches is 830 as shown in Table 3 and the full listing is available in Additional file 2.

\begin{tabular}{|c|c|c|}
\hline Gene Ontology term & Unique sequences & Percentage of total matches \\
\hline cell part & 280 & $33.73 \%$ \\
\hline intracellular part & 224 & $26.99 \%$ \\
\hline calcineurin complex & 2 & $0.24 \%$ \\
\hline cytoplasm & 152 & $18.31 \%$ \\
\hline cytoplasmic part & 132 & $15.90 \%$ \\
\hline intracellular organelle & 196 & $23.61 \%$ \\
\hline intracellular organelle part & 97 & $11.69 \%$ \\
\hline proteasome complex (sensu Eukaryota) & 10 & $1.20 \%$ \\
\hline proteasome regulatory particle (sensu Eukaryota) & 8 & $0.96 \%$ \\
\hline proton-transporting ATP synthase complex & 4 & $0.48 \%$ \\
\hline respiratory chain complex I & 3 & $0.36 \%$ \\
\hline respiratory chain complex III & 3 & $0.36 \%$ \\
\hline respiratory chain complex IV & 1 & $0.12 \%$ \\
\hline ribonucleoprotein complex & 35 & $4.22 \%$ \\
\hline RNA polymerase complex & 2 & $0.24 \%$ \\
\hline RNAi effector complex $(I)$ & I & $0.12 \%$ \\
\hline ubiquinol-cytochrome-c reductase complex & 3 & $0.36 \%$ \\
\hline membrane & 107 & $12.89 \%$ \\
\hline membrane part & 81 & $9.76 \%$ \\
\hline protein serine/threonine phosphatase complex & 2 & $0.24 \%$ \\
\hline envelope & 33 & $3.98 \%$ \\
\hline extracellular matrix & 10 & $1.20 \%$ \\
\hline extracellular matrix part & 6 & $0.72 \%$ \\
\hline extracellular region & 51 & $6.14 \%$ \\
\hline extracellular region part & 40 & $4.82 \%$ \\
\hline membrane-enclosed lumen & 2 & $0.24 \%$ \\
\hline organelle & 196 & $23.61 \%$ \\
\hline intracellular organelle & 196 & $23.61 \%$ \\
\hline membrane-bound organelle & 148 & $17.83 \%$ \\
\hline non-membrane-bound organelle & 68 & $8.19 \%$ \\
\hline organelle part & 97 & $11.69 \%$ \\
\hline vesicle & 8 & $0.96 \%$ \\
\hline organelle part & 97 & $11.69 \%$ \\
\hline protein complex & 102 & $12.29 \%$ \\
\hline synapse & 7 & $0.84 \%$ \\
\hline synapse part & 3 & $0.36 \%$ \\
\hline
\end{tabular}

sis gel (2\% agarose) for inserts of $100-2000$ bps. Amplicons (cDNA inserts) were purified using Millipore Montage PCR 96 Cleanup Kit (Billerica, MA). We checked the concentration of randomly selected purified cDNA using PicoGreen (Molecular Probes, Eugene, OR), which ranged from $100-500 \mathrm{ng} / \mu \mathrm{l}$ with an average of $240 \mathrm{ng} / \mu \mathrm{l}$. Four $\mu \mathrm{l}$ of the purified cDNA (55 $\mu \mathrm{l}$ in total) was sequenced using BigDye ${ }^{\circledast}$ Terminator v3.1 and a 16-capillary ABI PRISM ${ }^{\circledast} 3100$ Genetic Analyzer (Applied Biosystems, Foster City, CA) according to manufacturer's instruction.

\section{EST processing}

Many software programs are available that provide sequence cleansing and assembly. These include commercial software such as Sequencher (Gene Codes, Ann Arbor,
Michigan, USA), and Aligner (CodonCode, Dedham, MA, USA), and open source software such as CAP and TIGR Assembler. With these software packages it is possible to quickly remove vector sequences from each EST clone and screen the ESTs for low-quality sequences. The high-quality and trimmed EST sequences then can be used to find overlap assembly of contiguous sequences. Sequence information was stored in ABI chromatograph trace files, and Phred was used to perform base-calling [20]. Phred read DNA trace data, called bases, assigned quality values to the bases, and wrote the base calls and quality values to output sequence files in either FASTA or SCF format. Quality values for the bases were later used by the sequence assembly program, Phrap [21], to increase the accuracy of assembled sequences. Phred uses simple Fourier methods [22] to examine the four base traces in the 
Table 7: KEGG pathway mapping for Eisenia fetida unique sequences. The total number of mapped unique sequences is 157 . The full listing of pathways is available in Additional file 3.

\begin{tabular}{|c|c|c|c|}
\hline KEGG pathway & No. of unique sequence & $\begin{array}{l}\text { Percentage of total unique } \\
\text { sequences* }\end{array}$ & $\begin{array}{c}\text { No. of KEGG pathways } \\
\text { mapped }\end{array}$ \\
\hline Metabolism & 82 & $52 \%$ & 57 \\
\hline Carbohydrate Metabolism & 35 & $22 \%$ & 10 \\
\hline Energy Metabolism & 28 & $18 \%$ & 8 \\
\hline Nucleotide Metabolism & 2 & $1 \%$ & 2 \\
\hline Amino Acid Metabolism & 18 & $11 \%$ & 12 \\
\hline Metabolism of Other Amino Acids & 10 & $6 \%$ & 3 \\
\hline Glycan Biosynthesis and Metabolism & 6 & $4 \%$ & 8 \\
\hline Metabolism of Cofactors and Vitamins & 9 & $6 \%$ & 6 \\
\hline Biosynthesis of Secondary Metabolites & 2 & $1 \%$ & I \\
\hline Xenobiotics Biodegradation and Metabolism & 6 & $4 \%$ & 7 \\
\hline Genetic Information Processing & 28 & $18 \%$ & 6 \\
\hline Transcription & 2 & $1 \%$ & 2 \\
\hline Translation & 17 & $11 \%$ & 1 \\
\hline Folding, Sorting and Degradation & 9 & $6 \%$ & 3 \\
\hline Environmental Information Processing & 27 & $17 \%$ & 10 \\
\hline Membrane Transport & 1 & $1 \%$ & 1 \\
\hline Signal Transduction & 14 & $9 \%$ & 6 \\
\hline Signaling Molecules and Interaction & 13 & $8 \%$ & 3 \\
\hline Cellular Processes & 37 & $24 \%$ & 18 \\
\hline Cell Motility & 9 & $6 \%$ & 3 \\
\hline Cell Communication & 13 & $8 \%$ & 4 \\
\hline Endocrine System & 4 & $3 \%$ & 3 \\
\hline Immune System & 5 & $3 \%$ & 3 \\
\hline Nervous System & 8 & $5 \%$ & 2 \\
\hline Sensory System & 3 & $2 \%$ & I \\
\hline Development & 3 & $2 \%$ & 2 \\
\hline Human Diseases & 9 & $6 \%$ & 8 \\
\hline Neurodegenerative Disorders & 6 & $4 \%$ & 4 \\
\hline Metabolic Disorders & 2 & $1 \%$ & 2 \\
\hline Cancers & 2 & $1 \%$ & 2 \\
\hline
\end{tabular}

data set to predict a series of evenly spaced locations. It determines where the true peak location would be if there were no compressions, dropouts, or other factors shifting the peaks from their locations. Then Phred examines each trace to find the centers of the observed peaks and the areas of these peaks relative to their neighbors. A dynamic programming algorithm [23] is used to match the observed peaks detected in the second step with the predicted peak locations found in the first step. It uses a quality value lookup table to assign the corresponding quality value. The quality value is related to the base call error probability by the formula $Q V=-10 \times \log _{10}\left(P_{e}\right)$ where $P_{e}$ is the probability that the base call is an error [20].

Typically, sequence chromatograms have low-quality regions at the beginning and the end of each sequence read [24]. One can automatically remove the low-quality ends when quality values are available. This process is called "end clipping" or "end trimming". There are two different end clipping methods [24], (1) maximizing regions with error rates below a given threshold, and (2) using separate criteria at the start and the end of the sequence. We chose the former method which was implemented in CodonCode Aligner [25] to remove low quality bases at both ends by setting quality score $Q V \geq 20$ (or $P_{e}$ $\leq 0.01$ ). Flanking vector/adaptor sequences should also be trimmed off because they can lead to incorrect assemblies or alignment. We input a custom-made vector/adaptor file [24] into the Aligner [25] to trim vector/adaptor sequences. Furthermore, we used VecScreen [26] to detect and then manually removed any residual and partial vector contamination in our ESTs.

Phrap was used to assemble sequence fragments into a larger sequence by identifying overlaps between sample sequences [27]. Samples that can be joined together are put into "contigs". The following greedy algorithm is used in Phrap. First, it finds potential overlaps between samples by looking for shared 12-nucleotide "words" in the sequence. Then the pair of samples with highest number of shared words is found. If the alignment is good enough, it would be kept as a new contig, and the consensus sequence would be calculated; otherwise, the alignment would be rejected, and the two samples would be left sep- 


\begin{tabular}{|c|c|}
\hline \multirow{6}{*}{\multicolumn{2}{|c|}{\begin{tabular}{|l|} 
clone \\
cloneID: VARCHAR(40) \\
libID: VARCHAR(20) \\
@ company: VARCHAR(30) \\
\& sequence: TEXT \\
\& length: INTEGER(10) \\
\end{tabular}}} \\
\hline & \\
\hline & \\
\hline & \\
\hline & \\
\hline & \\
\hline go_subtype & \\
\hline queryID: VARCHAR(30) & \\
\hline ○ symbol: VARCHAR(20) & \\
\hline geneName: VARCHAR(100) & \\
\hline D type: VARCHAR(100) & \\
\hline ○ subtype: VARCHAR(100) & \\
\hline uniseghit & \\
\hline UniseqID: VARCHAR(60) & \\
\hline hitID: VARCHAR(20) & \\
\hline$\checkmark$ hitlength: INTEGER(8) & \\
\hline bitScore: INTEGER(8) & \\
\hline$\diamond$ evalue: VARCHAR(20) & \\
\hline$\diamond$ identity: VARCHAR(20) & \\
\hline$\ominus$ lastUpdate: DATE & \\
\hline pathwaynames & \\
\hline ECnumber: VARCHAR(100) & \\
\hline count: INTEGER(5) & \\
\hline$\ominus$ total_name: TEXT & \\
\hline name1: TEXT & \\
\hline name2: TEXT & \\
\hline name3: TEXT & \\
\hline O name4: TEXT & \\
\hline O name5: TEXT & \\
\hline name6: TEXT & \\
\hline$\checkmark$ name7: TEXT & \\
\hline O name8: TEXT & \\
\hline name9: TEXT & \\
\hline$\checkmark$ name10: TEXT & \\
\hline O name11: TEXT & \\
\hline$\checkmark$ name12: TEXT & \\
\hline name13: TEXT & \\
\hline O name14: TEXT & \\
\hline name15: TEXT & \\
\hline$\checkmark$ name16: TEXT & \\
\hline name17: TEXT & \\
\hline O name18: TEXT & \\
\hline O name19: TEXT & \\
\hline$\theta$ name20: TEXT & \\
\hline
\end{tabular}

\begin{tabular}{|c|c|}
\hline contigview & est_new \\
\hline$\checkmark$ name: VARCHAR(50) & estID: VARCHAR(50) \\
\hline length: INTEGER(11) & cloneID: VARCHAR(40) \\
\hline alignloc1: INTEGER(11) & $\ominus$ direction: CHAR(2) \\
\hline$\ominus$ singlet: INTEGER(11) & $\checkmark$ sequence: TEXT \\
\hline ○ alignloc2: INTEGER(11) & $\diamond$ seqlength: INTEGER(5) \\
\hline contig: VARCHAR(20) & $\diamond$ uniseqID: VARCHAR(40) \\
\hline Q contig_length: INTEGER(11) & $\diamond$ accessionID: VARCHAR( $(9)$ \\
\hline & putativeProtein: TINYTEXT \\
\hline pathwaypaths_update & lastUpdate: DATE \\
\hline O ECnumber: VARCHAR(30) & $\diamond$ submitNCBI: CHAR(3) \\
\hline
\end{tabular}

o category: VARCHAR(100)

o path: VARCHAR(100)

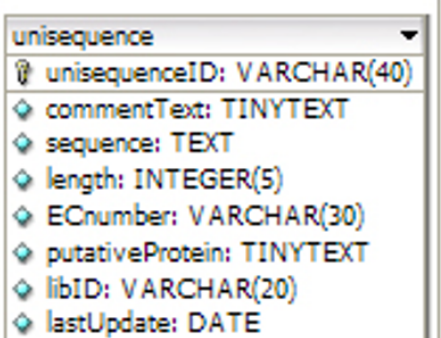

\section{$\diamond$ lastUpdate: DATE}

\begin{tabular}{|c|c|}
\hline \multicolumn{2}{|l|}{ master_pathway } \\
\hline$\checkmark$ unisequenceID: VARCHAR(40) & \\
\hline $\begin{array}{l}\ominus \text { uniSeq: TEXT } \\
\diamond \text { flybaseID: VARCHAR(16) }\end{array}$ & \\
\hline Q genebankID: VARCHAR(20) & \\
\hline symbol: VARCHAR(20) & \\
\hline$\checkmark$ geneName: VARCHAR(40) & \\
\hline$\triangle$ ECnumber: VARCHAR(30) & \\
\hline
\end{tabular}

\begin{tabular}{|l|}
\hline flybasedetails \\
\hline$\hat{Q}$ queryID: VARCHAR(30) \\
\hline
\end{tabular}

$\checkmark$ acessNum: VARCHAR(30)

Q hitID: VARCHAR(20)

Q score: INTEGER(8)

$\checkmark$ evalue: VARCHAR(30)

$\checkmark$ symbol: VARCHAR(20)

Q geneName: VARCHAR(40) \begin{tabular}{l|} 
master_search_nogo \\
$\vartheta$ labName: VARCHAR(40) \\
$\diamond$ institute: VARCHAR(50)
\end{tabular}

$\vartheta$ institute: VARCHAR(50)
$\diamond$ organismName: VARCHAR(80)

$\vartheta$ tissueType: TINYTEXT

$\vartheta$ unisequenceID: VARCHAR(40)

$\diamond$ uniseqlen: INTEGER( $(8)$

$\vartheta$ uniSeg: TEXT

- ECnumber: VARCHAR(30)

$\checkmark$ hitlength: INTEGER(8)

$\checkmark$ bitScore: INTEGER(8)

$\checkmark$ evalue: VARCHAR(20)

○ identity: VARCHAR(20)

O flybaseID: VARCHAR(16)

0 symbol: VARCHAR(20)

$\checkmark$ geneName: VARCHAR(100)

Q geneBankID: VARCHAR(20)

$\vartheta$ definition: TINYTEXT

$\diamond$ accessionID: TINYTEXT

$\vartheta$ organism: TINYTEXT

O ncbilink: TINYTEXT

Q cloneID: VARCHAR(40)

$\checkmark$ rawlen: INTEGER(5)

Q rawSeq: TEXT

○ cleanedlen: INTEGER(5)

$\checkmark$ cleanedSeg: TEXT

$\checkmark$ vector: VARCHAR(20)

\begin{tabular}{|l|}
\hline term \\
\hline id: INTEGER(11) \\
\hline name: VARCHAR(255) \\
$\ominus$ term_type: VARCHAR(55) \\
$\ominus$ acc: VARCHAR(32) \\
$\ominus$ is_obsolete: INTEGER(11) \\
$\diamond$ is_root: INTEGER(11) \\
\hline
\end{tabular}

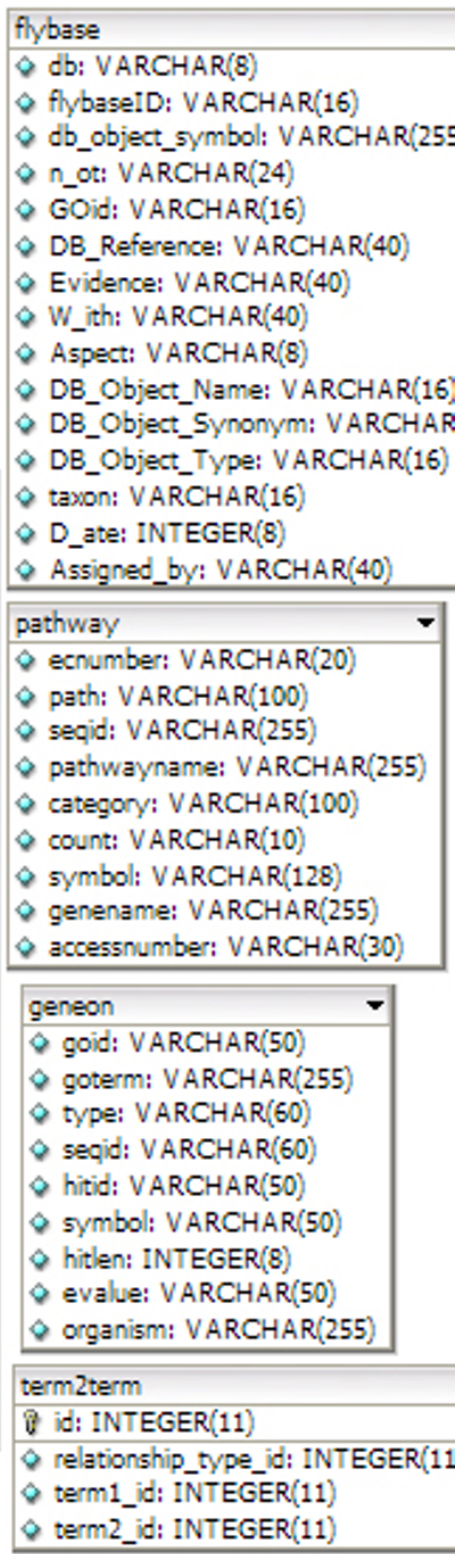

\section{Figure 2}

The ESTMD database schema showing tables, fields, and data types.

arated. Four criteria were used to determine whether to accept or reject an alignment: (1) minimum percent identity (the minimum percentage of identical bases in the aligned region) $\geq 70 \%$; (2) minimum overlap length $\geq 25$ bps, (3) minimum alignment score; which is similar to (2) but takes any mismatches into account, $\geq 20 \mathrm{bps}$; and (4) maximum gap size $\leq 15$ bps. Overall, these criteria were relatively relaxed if compared to more stringent set- tings such as $90 \%$ for minimum percentage identity or minimum overlap length $\geq 35 \mathrm{bps}$. If one sample has an insertion/deletion that is larger than 15 bps, the alignment will typically stop there, and the rest of the sample will be considered unaligned. The alignment process would be then repeated. If a sample is in a contig, the consensus sequence is then used for the contig. If the two samples are already in the same contig, the next pair is 


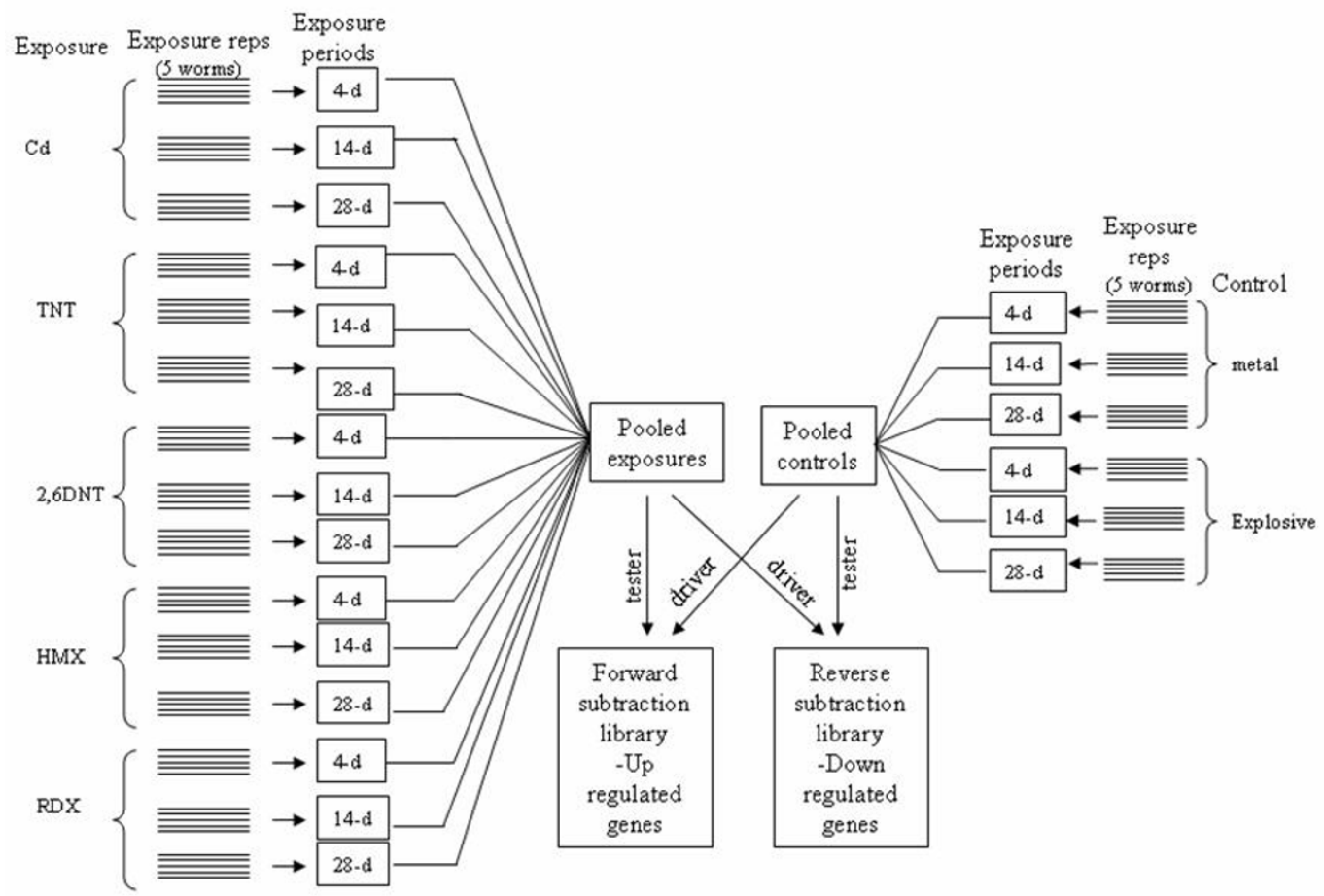

Figure 3

Scheme of RNA sample pooling for subtractive suppression hybridization cDNA library construction: the first library.

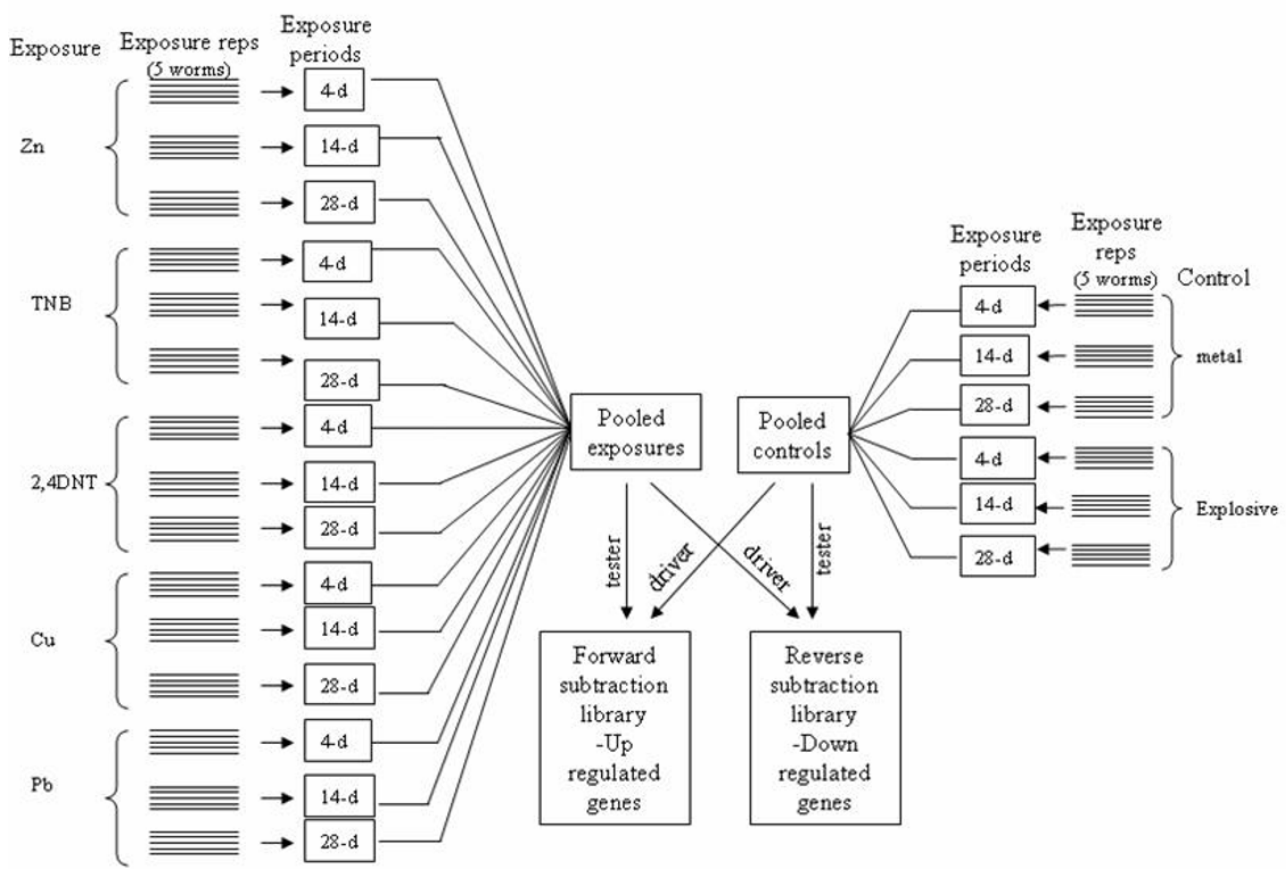

Figure 4

Scheme of RNA sample pooling for subtractive suppression hybridization cDNA library construction: the second library. 


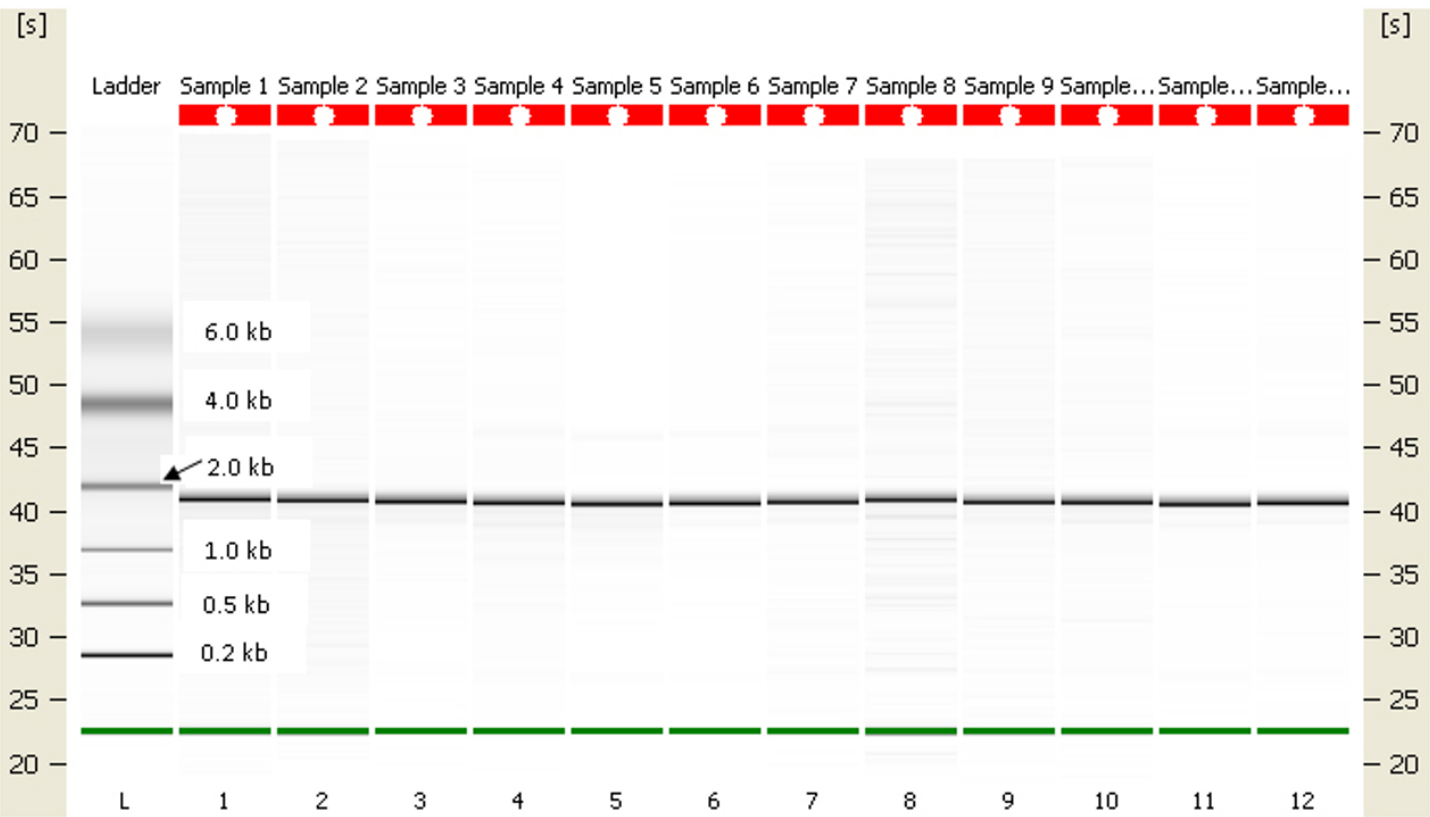

\section{Figure 5}

Earthworm total RNA electrophoresis using Agilent 2100 Bioanalyzer.

[s]

Ladder Sample 1 Sample 2 Sample 3 Sample 4 Sample 5 Sample 6 Sample 7 Sample 8 Sample 9 Sample... Sample... Sample...

$85-$

$80-$

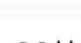

$75-$

$6.0 \mathrm{~kb}$

$-80$

$70-$

$4.0 \mathrm{~kb}$

$-75$

$65-$

$60-$

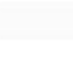

$-70$

$55-$

$2.0 \mathrm{~kb}$

$1.0 \mathrm{~kb}$

$-65$

$50-$

$45-$

40 -

$0.5 \mathrm{~kb}$

$0.2 \mathrm{~kb}$

$35-$

$30-$

25 -

$20-$
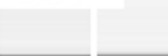

$-60$

$-55$

$-50$

$-45$

$-40$

$-35$

$-30$

$-25$

$15-$

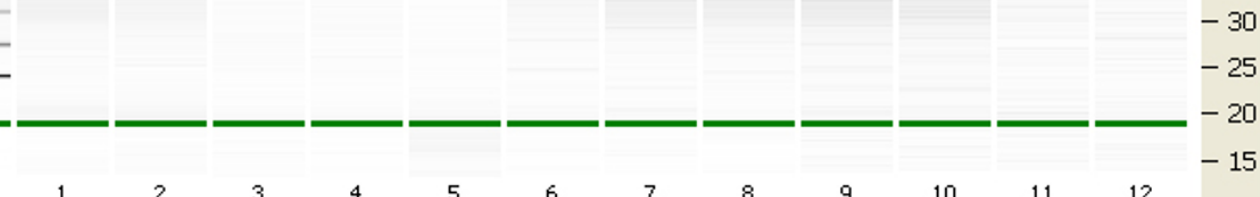

\section{Figure 6}

Earthworm purified mRNA electrophoresis using Agilent 2100 Bioanalyzer. 


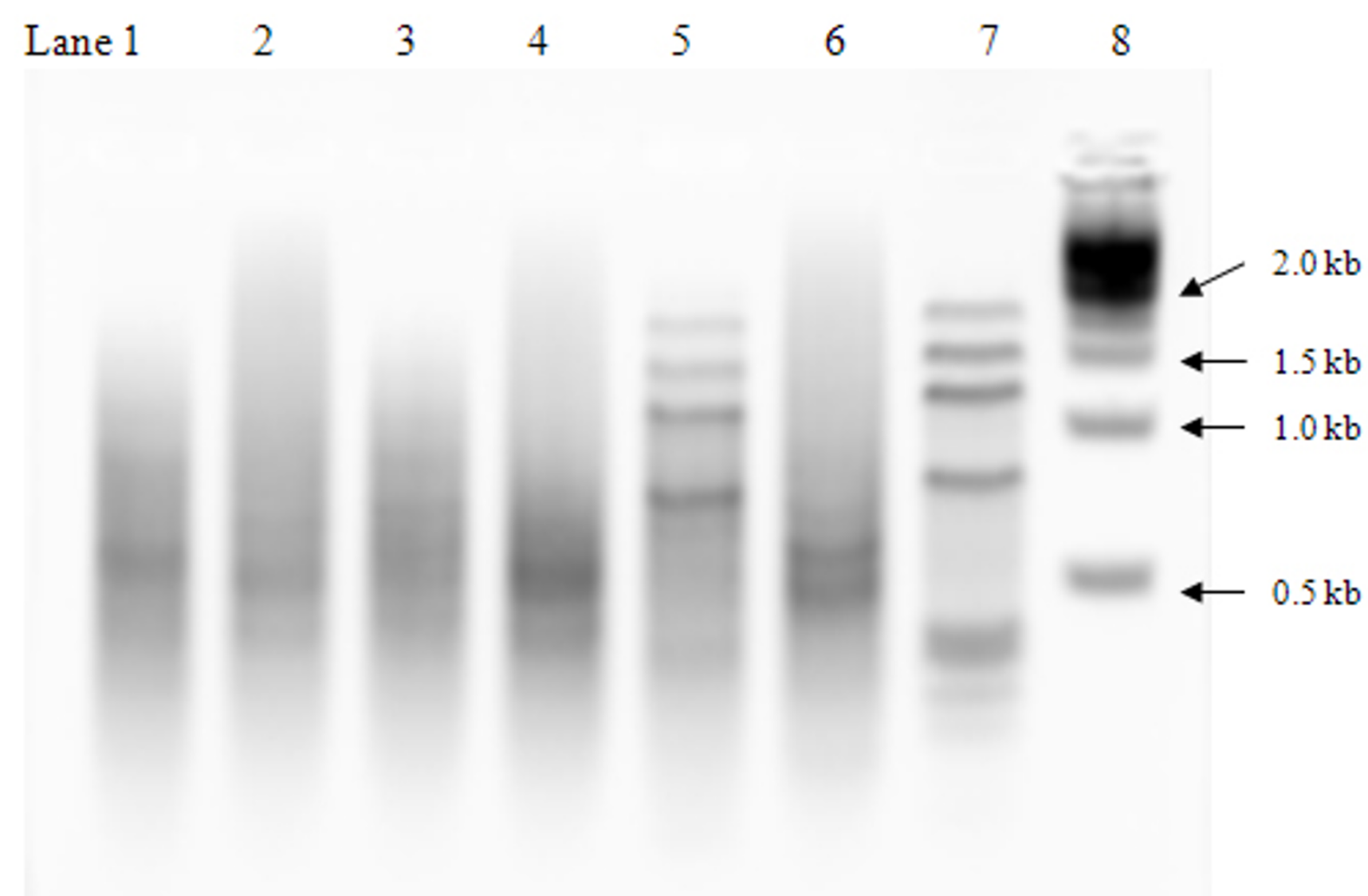

Figure 7

Subtracted and non-subtracted cDNAs electrophoresed on a $2 \%$ agarose/SybrGreen gel in Ix sodium borate buffer. Lane I: forward subtracted earthworm (EW) cDNA; Lane 2: forward non-subtracted EW cDNA; Lane 3: reverse subtracted EW cDNA; Lane 4: reverse non-subtracted EW cDNA; Lane 5: subtracted human skeleton muscle (HSM) cDNA; Lane 6: non-subtracted HSM cDNA; Lane 7: control subtracted human skeleton muscle cDNA; Lane 8: I kb DNA ladder.

retrieved and analyzed. It repeats and continues the pairwise joins until all possible joins have been tried, or until the maximum number of merge failures in a row has occurred.

After assembly, all contigs with more than three ESTs were assessed for missassemblies using the assembly viewer Consed [28]. Contigs flagged for possible missassemblies were manually edited using Consed tools to remove potential chimeric ESTs or other suspect ESTs. Chimerism occurs because of multiple insert cloning or mistracking of sequence gel lanes. After assembly with Phrap, contigs with more than three ESTs were examined again in Consed to eliminate additional missassemblies not resolved by Phrap. Any bps with a calculated quality value below 12 was changed to an $\mathrm{N}$ (unknown base) which was considered as a suspect ESTs.

\section{EST comparative analysis and functional assignment}

Comparative analysis was performed using blastx through NCBI with the unique sequences (including the consensus sequences of assembled contigs and the singletons). Blastx searches were conducted on our local BLAST server against the NCBI's non-redundant peptide sequence database. The returned search results (100 best hits) were transferred automatically into a relational database. We discarded hits with an $E$-value $>10^{-5}$ and sorted out the remaining hits by organism name. To assign putative functions to the unique E. fetida sequences, we extracted the GO hierarchical terms of their homologous genes from the protein databases of the following four model organisms: Mus musculus, Drosophila melanogaster, Caenorhabditis elegans, and Saccharomyces cerevisiae [2931]. Meanwhile, we also mapped the unique sequences to metabolic pathways in accordance with the KEGG [32]. Enzyme commission (EC) numbers [33] were acquired for the unique sequences by blastx searching (E-value $\leq$ 


\section{ESTMD Three-Tier Architecture}

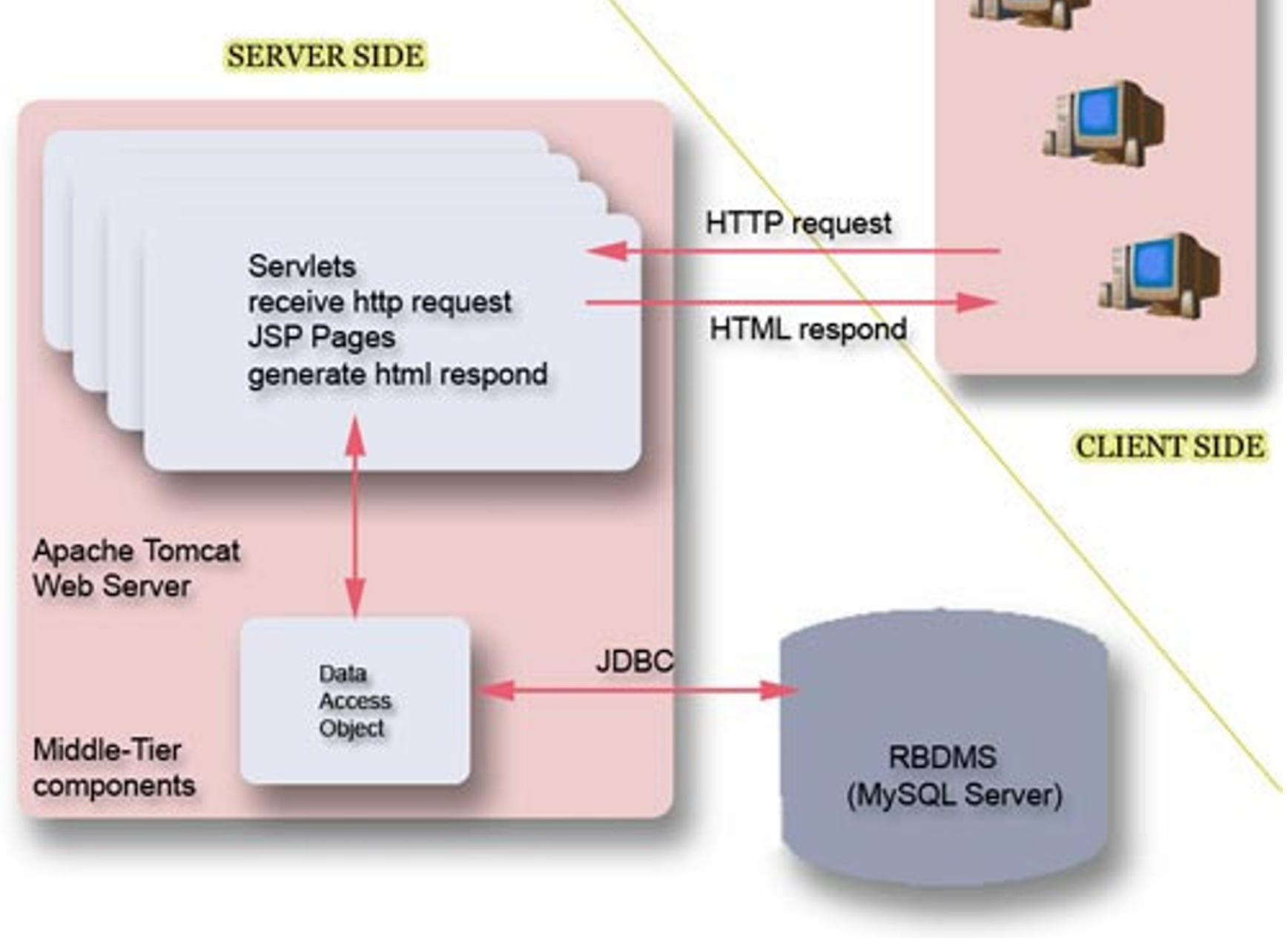

Figure 8

The architecture of ESTMD web application and database.

$10^{-5}$ ) the SWIR database, which is made up from three protein databases WormPep, SwissProt and Trembl. The EC numbers were then used to putatively map unique sequences to specific biochemical pathways $[6,7]$. All the matched GO and pathway information was automatically stored in our local relational database.

\section{EST database implementation and web application}

To facilitate efficient management and retrieval of the EST information obtained from this project, we upgraded our previous developed EST model database (ESTMD version 1) [6] and integrated the earthworm EST information into the new version of ESTMD. The current implementation of ESTMD (version 2) has many new features. The main changes include further normalization of tables from 50 tables to 17, altering main tables to be capable of storing multiple organism information, adding a new table (contigview) to store view information, using a 2D Java class for displaying contigs instead of a Perl script, and implementing the whole web application as a unified portable web module.

ESTMD is currently hosted on Suse Linux 10 and can be implemented in MySQL 4.0 or higher version. It has an integrated web-based application with a three-tier structure, i.e., client, sever and backend database (Figure 8). The web-based interface of the database was created using HTML and JavaScript to evaluate the validation of the input on the client side and to reduce the burden on the server side. Apache 2.2 is used as the HTTP web server, 
while Tomcat 5.5 is the Servlets container. Both of these programs were developed and maintained on Linux and WinNT, ensuring that the database is transplantable and platform-independent. The server-side programs are implemented by Java 2 Enterprise Edition (J2EE) technologies. Servlet and JSP (JavaServer Pages) are used to communicate between users and databases and to implement a query.

\section{Abbreviations \\ COX Cytochrome c Oxidase}

DBH Dopamine-Beta-Hydroxylase

DNT (2,4-DNT) 2,4-dinitrotoluene

DNT (2,6-DNT) 2,6-dinitrotoluene

EST Expressed Sequence Tags

ESTMD Expressed Sequence Tags Model Database

GO Gene Ontology

HMX octahydro-1,3,5,7-tetranitro-1,3,5,7-tetrazocine

J2EE Java 2 Enterprise Edition

JSP JavaServer Pages

KEGG Kyoto Encyclopedia of Genes and Genomes

ORCs Ordnance Related Compounds

RDX 1,3,5-trinitro-1,3,5-triazacyclohexane

SSH Suppression Subtractive Hybridization

SOD Cu/Zn-superoxide Dismutase

TNB 1,3,5-trinitrobenzene

TNT 2,4,6-trinitrotoluene

\section{Competing interests}

The authors declare that they have no competing interests.

\section{Authors' contributions}

YD, PG and EJP initiated the study. LSI performed worm exposure. XG and PG conducted RNA isolation, cDNA cloning and sequencing. MP, YD and PG designed the framework for data analysis and interpretation of data. $\mathrm{MP}$ and YD designed and implemented cleansing and assembling process, blast extraction, gene ontology, and pathway analysis. KY implemented a local blast for EST data analysis and participated in cleansing and assembling process. MP and YD designed and implemented the database, normalized tables, data management, web server configuration and web application programming. MP and PG drafted the original manuscript. YD, PG and EJP coordinated and directed the project. All authors have read and approved the final manuscript.

\section{Additional material}

\section{Additional file 1}

A complete listing of significant blastx hits $(E \leq 10-5)$ of the 2231 unique Eisenia fetida EST sequences matching four model organisms Mus musculus, Drosophila melanogaster, Caenorhabditis elegans, and Saccharomyces cerevisiae.

Click here for file

[http://www.biomedcentral.com/content/supplementary/14712105-8-S7-S7-S1.doc]

\section{Additional file 2}

A complete listing of 5129 GO terms for the 517 unique Eisenia fetida sequences with significant homology with 830 genes of the four model organisms.

Click here for file

[http://www.biomedcentral.com/content/supplementary/1471-

2105-8-S7-S7-S2.xls]

\section{Additional file 3}

A complete listing of the KEGG pathways mapped for 157 unique Eisenia fetida sequences.

Click here for file

[http://www.biomedcentral.com/content/supplementary/14712105-8-S7-S7-S3.doc]

\section{Acknowledgements}

We thank Robert Boyd and Rebecca Athow for their technical assistance. This work was supported by the Army Environmental Quality Program of the US Army Corps of Engineers under contract \#W912HZ-05-P-0145 and the Mississippi Functional Genomics Network (DHHS/NIH/NCRR Grant\# 2P20RR016476-04). Permission was granted by the Chief of Engineers to publish this information.

This article has been published as part of BMC Bioinformatics Volume 8 Supplement 7, 2007: Proceedings of the Fourth Annual MCBIOS Conference. Computational Frontiers in Biomedicine. The full contents of the supplement are available online at http://www.biomedcentral.com//47/-2105/ 8? issue $=$ S7.

\section{References}

I. Edwards CA, (Ed): Earthworm Ecology Second edition. CRC Press, Boca Raton, FL; 2004.

2. Reynolds JW: The status of earthworm biogeography, diversity, and taxonomy in North America revisited with glimpses into the future. In Earthworm Ecology 2nd edition. Edited by: Edwards CA. CRC Press, Boca Raton, FL, USA; 2004:63-74.

3. Reynolds JW: Status of exotic earthworm systematics and biogeography in North America. In Earthworm Ecology and Biogeography Edited by: Hendrix PF. Lewis Publishers, CRC Press, Boca Raton, FL; 1995:I-28. 
4. Sturzenbaum SR, Parkinson J, Blaxter M, Morgan AJ, Kille P, Georgiev $O$ : The earthworm expressed sequence tag project. Pedobiologia 2003, 47:447-45I.

5. Lee MS, Cho SJ, Tak ES, Lee JA, Cho HJ, Park BJ, Shin C, Kim DK, Park SC: Transcriptome analysis in the midgut of the earthworm (Eisenia andrei) using expressed sequence tags. Biochem Biophys Res Commun 2005, 328(4): I I 96-204.

6. Deng $Y$, Dong $Y$, Thodima V, Clem RJ, Passarelli AL: Analysis and functional annotation of expressed sequence tags from the fall armyworm Spodoptera frugiperda. BMC Genomics 2006, 7:264.

7. McCarter JP, Mitreva MD, Martin J, Dante M, Wylie T, Rao U, Pape D, Bowers Y, Theising B, Murphy CV, Kloek AP, Chiapelli BJ, Clifton SW, Bird DM, Waterston RH: Analysis and functional classification of transcripts from the nematode Meloidogyne incognita. Genome Biol 2003, 4(4):R26.

8. Wang J, Jemielity S, Uva P, Wurm Y, Graff J, Keller L: An annotated cDNA library and microarray for large-scale gene-expression studies in the ant Solenopsis invicta. Genome Biol 2007, 8:R9.

9. Yang GP, Ross DT, Kuang WW, Brown PO, Weigel RJ: Combining SSH and cDNA microarrays for rapid identification of differentially expressed genes. Nucleic Acids Res 1999, 27(6):1517-23.

10. Ghorbel MT, Sharman G, Hindmarch C, Becker KG, Barrett T, Murphy $D$ : Microarray screening of suppression subtractive hybridization-PCR cDNA libraries identifies novel RNAs regulated by dehydration in the rat supraoptic nucleus. Physiol Genomics 2006, 24(2): I63-72.

II. Soetaert A, Moens LN, Van der Ven K, Van Leemput K, Naudts B, Blust R, De Coen WM: Molecular impact of propiconazole on Daphnia magna using a reproduction-related cDNA array. Comp Biochem Physiol C Toxicol Pharmacol 2006, I 42(I-2):66-76.

12. Rim KT, Park KK, Sung JH, Chung YH, Han JH, Cho KS, Kim KJ, Yu I): Gene-expression profiling using suppression-subtractive hybridization and cDNA microarray in rat mononuclear cells in response to welding-fume exposure. Toxicol Ind Health 2004, 20(I-5):77-88.

13. Gong P, Guan X, Inouye LS, Pirooznia M, Indest KJ, Athow RS, Deng $Y$, Perkins EJ: Toxicogenomics analysis provides new insights into molecular mechanisms of the sublethal toxicity of 2,4,6trinitrotoluene in Eisenia fetida. Environ Sci Technol 2007 in press.

14. Gong P, Inouye LS, Guan X, Indest KJ, Perkins EJ: Interactive effects between TNT and RDX on the earthworm Eisenia fetida using a 4 k-cDNA microarray. Abstract Book of SETAC North America 27th Annual Meeting, November 5-9, 2006, Montreal, PQ :364.

I5. Demuynck S, Grumiaux F, Mottier V, Schikorski D, Lemiere S, Lepretre A: Metallothionein response following cadmium exposure in the oligochaete Eisenia fetida. Comp Biochem Physiol C Toxicol Pharmacol 2006, I44(I):34-46.

16. Brulle F, Mitta G, Cocquerelle C, Vieau D, Lemiere S, Lepretre A, Vandenbulcke F: Cloning and real-time PCR testing of I4 potential biomarkers in Eisenia fetida following cadmium exposure. Environ Sci Technol 2006, 40(8):2844-50.

17. Brulle F, Mitta G, Leroux R, Lemiere S, Lepretre A, Vandenbulcke F: The strong induction of metallothionein gene following cadmium exposure transiently affects the expression of many genes in Eisenia fetida: a trade-off mechanism? Comp Biochem Physiol C Toxicol Pharmacol 2007, I 44(4):334-4I.

18. Galay-Burgos M, Spurgeon DJ, Weeks JM, Sturzenbaum SR, Morgan AJ, Kille P: Developing a new method for soil pollution monitoring using molecular genetic biomarkers. Biomarkers 2003, 8(3-4):229-39.

19. Diatchenko L, Lau YF, Campbell AP, Chenchik A, Moqadam F, Huang B, Lukyanov S, Lukyanov K, Gurskaya N, Sverdlov ED, Siebert PD: Suppression subtractive hybridization: A method for generating differentially regulated or tissue-specific cDNA probes and libraries. Proc Natl Acad Sci USA 1996, 93( I 2):6025-6030.

20. Ewing $B$, Green P: Base-calling of automated sequencer traces using phred. II. Error probabilites. Genome Res 1998, 8: I86-I94.

21. Nickerson DA, Tobe VO, Taylor SL: PolyPhred: automating the detection and genotyping of single nucleotide substitutions using fluorescence-based resequencing. Nucleic Acids Res 1997, 25:2745-275I.

22. Press WH, Flannery BP, Teukolsky SA, Vetterling WT: Numerical recipes in C++: The art of scientific computing. Cambridge University Press, Cambridge, UK; 1988.
23. Giegerich R, Meyer C, Steffen P: A discipline of dynamic programming over sequence data. Sci Comput Program 2004, 5 I (3):215-263.

24. Chou $\mathrm{HH}$, Holmes $\mathrm{MH}$ : DNA sequence quality trimming and vector removal. Bioinformatics 2001, I 7:1093-I I04.

25. CodonCode [http://www.codoncode.com/aligner/]

26. VecScreen [http://www.ncbi.nlm.nih.gov/VecScreen/Vec Screen.html]

27. Phred/Phrap/Consed; Shotgun sequence assembly [http:// www.phrap.org]

28. Gordon D, Abajian C, Green P: Consed: A Graphical Tool for Sequence Finishing. Genome Research 1998, 8:195-202

29. Ashburner M, Ball CA, Blake JA, Botstein D, Butler $H$, Cherry JM, Davis AP, Dolinski K, Dwight SS, Eppig JT, et al.: Gene ontology: tool for the unification of biology. The Gene Ontology Consortium. Nat Genet 2000, 25:25-29.

30. Gene Ontology Consortium: Creating the gene ontology resource: design and implementation. Genome Res 200I, I I:|425-1433.

3I. Harris MA, Clark J, Ireland A, Lomax J, Ashburner M, Foulger R, Eilbeck K, Lewis S, Marshall B, Mungall C, et al.: The Gene Ontology (GO) database and informatics resource. Nucleic Acids Res 2004, 32:D258-D26I

32. Ogata H, Goto S, Sato K, Fujibuchi W, Bono H, Kanehisa M: KEGG: Kyoto Encyclopedia of Genes and Genomes. Nucleic Acids Res 1999, 27:29-34.

33. IUBMB: Enzyme nomenclature: Recomendations of the nomenclature committee of the international union of biochemistry and molecular biology. Academic Press, San Diego, CA; 1992.
Publish with Bio Med Central and every scientist can read your work free of charge

"BioMed Central will be the most significant development for disseminating the results of biomedical research in our lifetime. "

Sir Paul Nurse, Cancer Research UK

Your research papers will be:

- available free of charge to the entire biomedical community

- peer reviewed and published immediately upon acceptance

- cited in PubMed and archived on PubMed Central

- yours - you keep the copyright

Submit your manuscript here:

http://www.biomedcentral.com/info/publishing_adv.asp
BioMedcentral 